\title{
Attitudes towards climate change migrants
}

\section{Marc Helbling ${ }^{1}$}

Received: 29 May 2019 / Accepted: 9 March 2020 / Published online: 18 March 2020

(C) The Author(s) 2020

\begin{abstract}
While climate change has become a salient political and social issue in Western societies, we know relatively little about how these societies will react to one of the potentially important consequences of climate change: increasing migration flows. By means of a representative online survey in Germany, this paper therefore investigates for the very first time to what extent citizens in industrialized societies are willing to accept climate change migrants, especially in comparison with other groups of migrants and refugees, and the circumstances and principles under which they would accept them. The findings show that climate change migrants receive high support levels comparable with those enjoyed by political refugees (migrants who need special protection) and that contrast with attitudes towards economic migrants (who are often not seen as in need of special protection). We also see that people are more likely to accept justifications for taking climate change migrants when they realize that the expected number of migrants is relatively low. While arguments about morality, corrective justice, and a country's capacity lead to similar acceptance rates in general, the latter argument plays a more important role for highly educated people and non-environmentalists than the former two. The findings of this study allow us to better prepare for potential conflicts that might emerge with increasing migration flows caused by climate change.
\end{abstract}

Keywords Climate change $\cdot$ Migration $\cdot$ Prejudices

\section{Introduction}

Various studies have shown that Western societies see climate change as an important problem (McCright et al. 2015). Various political debates are conducted on how to stop or slow down climate change (Bechtel and Scheve 2013). At the same time, mostly economists have started to investigate how climate change affects migration flows (Beine and Parsons 2015), how these flows can be regulated, and to what extent there is a moral obligation to accept migrants

Marc Helbling

helbling@wzb.eu

1 University of Bamberg, Bamberg, Germany 
forced to leave their home countries due to environmental changes (Wyman 2013). However, to the best of our knowledge, there is not a single study on how open Western societies are towards climate change migrants and whether or not they feel morally obliged to help these migrants (Dustmann and Okatenko 2011).

It has been argued that, under international human rights law, states are obliged to protect people whose lives are threatened by natural disasters and climate change (Burson et al. 2018: 407). These are people who are "forced to leave their traditional habitat, temporarily or permanently, because of a marked environmental disruption (natural and/or triggered by people) that jeopardized their existence and/or seriously affected their quality of life" (ElHinnawi 1985: 4, cited in McAdam 2012: 3). Climate migrants, however, do not constitute a legal category, and there is no legal basis for claiming asylum for environmental reasons (McAdam 2012). ${ }^{1}$ Accordingly, the United Nations Refugee Agency, UNHCR, prefers to speak of "persons displaced in the context of disasters and climate change."2

In general, there is hardly any research looking specifically at climate change, social psychological aspects, and intergroup relations together (Pearson et al. 2016). This stands in stark contrast to the growing literature on attitudes towards migrants more generally and at refugees who were forced to leave their countries in particular (Hainmueller and Hopkins 2014). To close this gap, this study asks two questions: (1) To what extent are citizens in industrialized societies willing to accept climate change migrants, especially in comparison with other groups of migrants? (2) Under which circumstances and according to which principles are they willing to accept them? Answers to these questions are crucial in understanding the extent to which Western societies are willing to bear the consequences of climate change to which they substantially contributed and to better prepare governments for potential conflicts that might emerge with the increasing migration flows.

To answer these questions, a representative online survey was carried out in Germany in June 2018. The increasing number of migrants in Germany since 2015 has demonstrated to what extent migration issues can polarize a society (Hager and Veit 2019). It can thus be assumed that Germans have strong opinions about migrants. As a highly industrialized country, Germany is also one of the main emitters of greenhouse gases. It is likewise among the six most desirable migration destination countries in the world (Laczko et al. 2017: 8).

\section{Reasons to migrate}

In a first experiment with a factorial survey design, people were randomly confronted with fictitious migrants who had left their countries for either economic, political, or

\footnotetext{
${ }^{1}$ Throughout the text, the term "climate change migrants" is used even though the term climate change refugees is often used in public debates. "Migrant" is the more general category for people who leave their home regions/ countries to take up residence in another region/country (permanently or temporarily). Even though the term "refugee" is often used for people that are forced to leave their home regions/countries for various reasons (political, economic, and environmental), according to its legal definition it includes persons who leave their home regions/countries "owing to well-founded fear of being persecuted for reasons of race, religion, nationality, membership of a particular social group or political opinion" (1951 Convention relating to the Status of Refugees).

${ }^{2}$ See: https://www.unhcr.org/en-us/climate-change-and-disasters.html (accessed 24 October 2019).
} 
environmental reasons. Two kinds of environmental reasons-droughts and sea level rises-are differentiated that constitute two slow-onset and long-term environmental changes that are very prominent and widely discussed consequences of climate change (Piguet et al. 2011: 8-11). As there has to date been no research on the perception of environmental migration, it was unclear at the outset of this study whether certain climate change migrants might be regarded as different and as more or less legitimate groups to be accepted as migrants than others. Accordingly, there was no basis for drawing hypotheses on whether and to what extent people make a distinction between these two reasons.

The study compares environmental migrants with economic migrants (who have left their countries due to increasingly dire economic situations) and political migrants (who were persecuted for their political convictions). The latter are very often seen as legitimate or genuine refugees in need of protection, also because they are recognized as refugees through the 1951 Geneva Refugee Convention. Economic migrants, however, are very often not considered as refugees, as they are not seen as people who were forced to leave their country but rather as migrants who try to take advantage of the economic situation in other countries (Verkuyten 2004). For these reasons, people are much more willing to accept political than economic migrants (Bansak et al. 2016; Hager and Vink 2019). ${ }^{3}$

The fictitious migrants in our study were either high- or low-skilled and were Christians or Muslims. This setup allowed us to put the degree of openness towards climate change migrants into perspective by comparing these attitudes with attitudes towards migrant groups that are already widely discussed and to take into account the economic (skills) and cultural (religion) migrant characteristics seen as particularly relevant to understanding attitudes towards migrants (Valentino et al. 2019).

The question at hand is whether climate change migrants are considered people in need of protection or not. On the one hand, they can be compared with political migrants as they have been forced to leave their countries due to circumstances for which they cannot be made responsible and that may even threaten their lives. Acceptance rates for these migrants might therefore be as high as those of political migrants. On the other hand, one might also expect attitudes to climate change migrants to be negative, because like economic migrants, climate change migrants leave their countries largely as a result of climate change's detrimental impact on national economies. It has been shown that rising temperatures reduce economic growth in regard to agricultural productivity, industrial output, and investment (Dell et al. 2012). While there are several studies that show that climate change leads to migration, it is unclear to what extent these movements are caused by direct impacts (e.g., flights from natural disasters) or indirect impacts (when people leave after the economy deteriorates due to increasing temperature and changing rainfall patterns) (Beine and Parsons 2015). Thus, if climate change migrants are seen as economic migrants, one can expect relatively low acceptance rates.

A representative survey $\left(N=1^{\prime} 102\right)$ from an online panel executed by the survey firm Respondi was fielded in Germany in June 2018. The sample included people above the age of 18 with German nationality who were sampled according to their gender, age, and education. ${ }^{4}$

\footnotetext{
${ }^{3}$ There are also other reasons that are considered legitimate grounds to be accepted as a refugee, such as persecution for reasons of race, religion, or nationality (see footnote 1). Bansak et al. (2016) have shown that Europeans do not differentiate between political, religious, and ethnic persecutions.

${ }^{4}$ For more information on the Respondi access panel: https://www.respondi.com/.
} 
Each respondent was presented with one short description of fictitious migrants and asked whether Germany should let this person immigrate (see Tables 1 and 2 in the Appendix for question wording and descriptive statistics). The vignettes looked as follows (randomizing the parts in italics, for balance tests see Table 3 in Appendix) $)^{5}$ :

We would now like to discuss the following case of a migrant who likes to come to Germany. He is 29 years old and has no family. He has a university degree/a high school degree and is Muslim/Christian.

He wants to immigrate to Germany as he is persecuted in his country for his political convictions due to a new authoritarian regime/he cannot find a job in his country due to the increasingly dire economic situation/his entire home country is becoming inhabitable due to soaring droughts/his entire home country is becoming uninhabitable due to sea level rises.

Graph 1 displays the marginal means of acceptance rates of people who agree to let in migrants with different reasons for migration and different economic and cultural characteristics. Confirming earlier studies, we see that many more people agree to accept political migrants (66\%) in comparison with economic migrants (48\%) (see also Table 5 for more detailed regression analyses). As for migrants who left their country because of increasing droughts or sea levels, we see that attitudes towards these two groups are pretty similar (60 and 63\%) and that the degree of acceptance is comparable with that of political migrants. Climate change migrants are thus clearly not seen as economic migrants even though these two categories are highly interrelated. The mean differences between economic migrants, on the one hand, and political and environmental migrants, on the other hand, are statistically significant at conventional levels (see Table 5). Ultimately, they are perceived as people in need of protection who were forced to leave their country, similarly to political migrants.

To put the attitudes towards migrants with different reasons for migration into perspective, Graph 1 also displays average attitudes towards migrants with different religions and educations. Muslims and low-skilled migrants face more opposition than Christians and low-skilled migrants, however not as much as economic migrants. Thus, it appears that the reason for migration leads to more polarization than migrant characteristics such as skills and religion.

It was likewise assessed whether preferences for reasons of migration vary across persons with different characteristics or whether one could expect the same attitudes from everyone surveyed. Attitude patterns may differ between people who hold generally negative or positive attitudes towards migrants. Further, respondents with rather extreme attitudes might not differentiate between different groups of migrants. For this reason, a closer look at the attitudes of both low- and high-skilled people has been taken, as numerous studies have shown that education is an important predictor for xenophobia and tolerance (Lancee and Sarrasin 2015). Moreover, a differentiation between environmentalists and non-environmentalist was made; as given the topic of environmental change, people who care more about the environment may be more sensitive to environmental migration than others.

\footnotetext{
${ }^{5}$ Since questions on climate change migrants have never been asked in any surveys so far (contrary to questions on political and economic migrants), two versions of the climate change vignettes have been tested. In one version, reference to droughts and sea level rises was made. In the second version, it was specified that these droughts and sea level rises were caused by climate change. The marginal means of acceptance rates of these two versions are very similar, and the differences are not statistically significant. The first version has been used for the analyses. Building an index out of the two versions leads to very similar results as appears in Table A6 in the Appendix.
} 


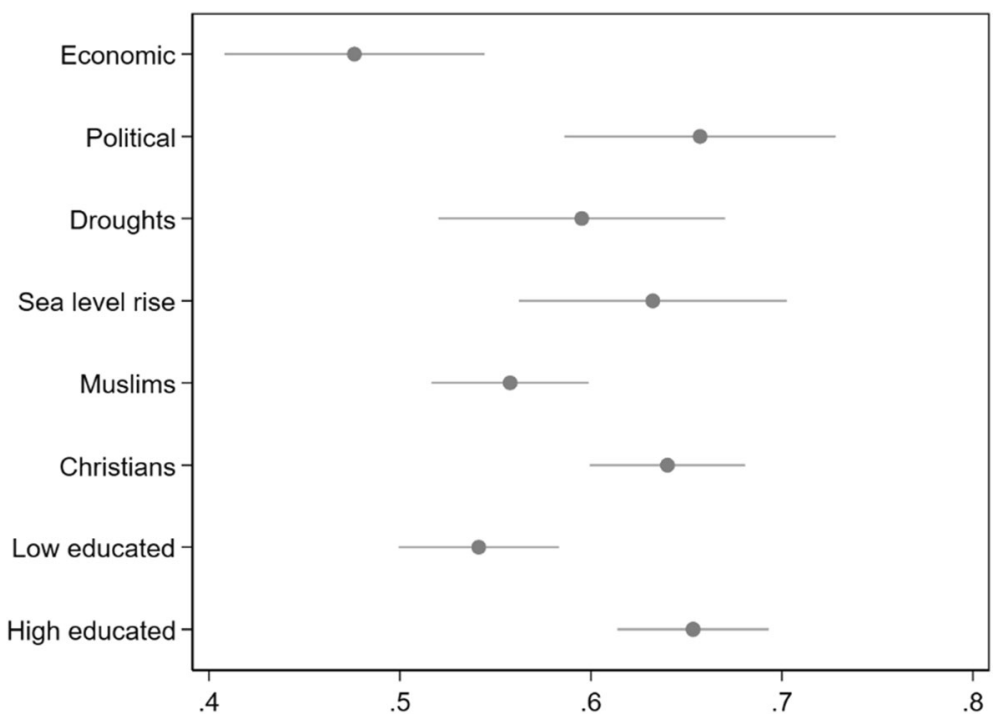

Graph 1 Immigration acceptance. Marginal means to accept migrants who left their home countries for different reasons and have different characteristics. Point estimates with 95\% confidence intervals (CI). $N=1$ '102. For more details, see Table 5 in the Appendix

To differentiate between high-skilled and low-skilled persons, the survey asked participants to indicate their highest educational degree. Respondents were separated into those who have a university entry diploma and those who do not. To differentiate environmentalists from nonenvironmentalists, an index was constructed out of the three following questions:

How often do you make a special effort to buy fruits and vegetables grown without pesticides or chemicals?

How often do you cut back on driving a car for environmental reasons?

How often do you sort glass, cans, plastic or paper and so on for recycling?

On a scale from 1 to 4 , respondents could indicate how often they do these things. The index was split along the mean value of 2.1 .

We see in Graph 2 that the pattern we observed in Graph 1 is very similar across the four subgroups and that people make a clear distinction between economic and other migrants, irrespective of their education or environmental attitudes (see also Table 5 in the Appendix). ${ }^{6}$ Across all types of migrants presented to participants, low-skilled people (54\%) and nonenvironmentalists (57\%) are on average less willing to accept migrants in comparison with high-skilled people and environmentalists (both 63\%).

\section{Reasons to accept climate change migrants}

Having shown that, on average, German citizens are relatively open towards climate change migrants, it would be interesting to know under which circumstances and according to which

\footnotetext{
${ }^{6}$ In some cases, especially "droughts," it appears that the mean differences are significantly different at the 0.1 level, only.
} 

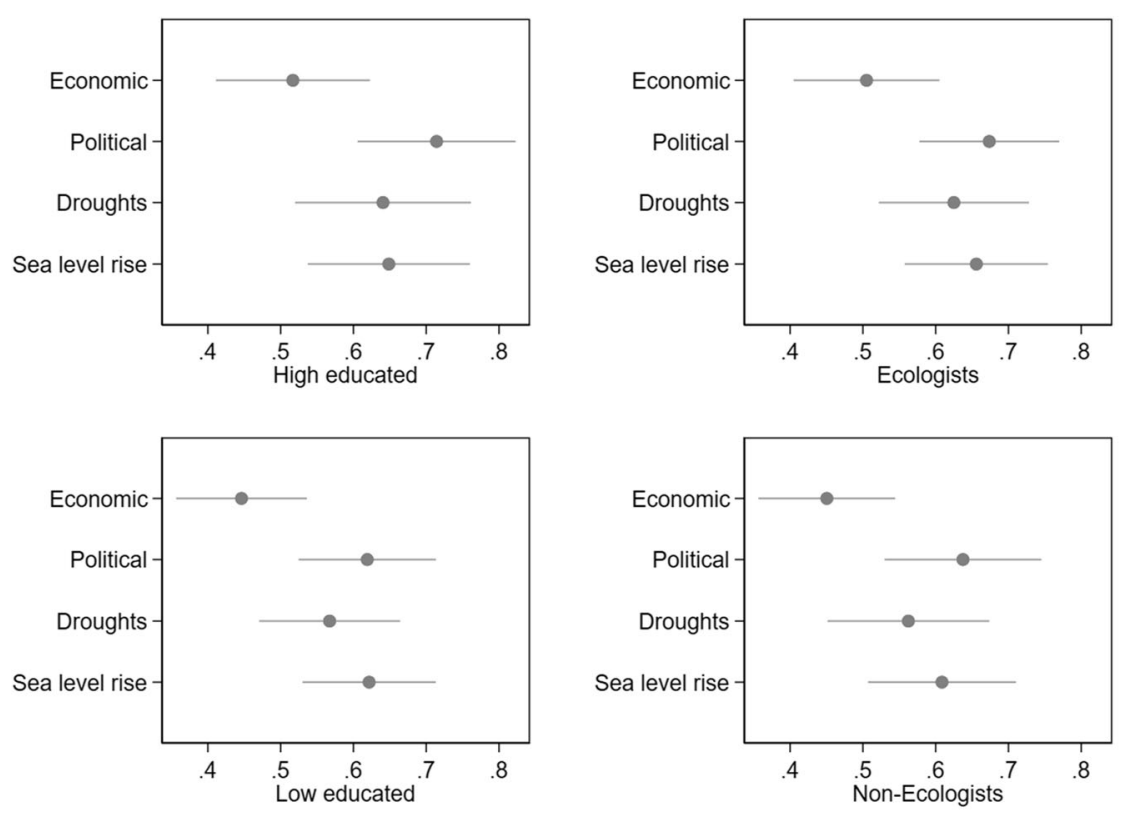

Graph 2 Immigration acceptance across subgroups. Marginal means to accept migrants who left their home countries for different reasons. Point estimates with $95 \%$ confidence intervals (CI). $N=1^{\prime} 102$. For more details, see Table 5 in the Appendix

principles they would be willing to accept them. A second framing experiment randomly asked respondents to express their agreement with three arguments for accepting climate change migrants: (1) a moral obligation to help people in distress in general; (2) an obligation to help climate change refugees in proportion to one's country capacities (population size, GDP, past number of accepted migrants); and (3) an obligation to help climate change refugees in proportion to one's country's greenhouse emissions (environmental responsibility that leads to climate change).

According to the first and most general argument, Western states have to help, as they have a moral obligation to support people in distress in general (Wyman 2013: 190-193). Climate change migrants, like refugees, constitute vulnerable persons. And as long as the help comes at little cost, states have an obligation to accept such people (Wyman 2017: 354-356). Inhabitants from islands that will soon disappear due to rising sea levels can clearly be considered people in urgent need. Likewise, these populations are very small, and thus the costs for receiving states are relatively small. Most climate change migrants, however, are affected by deteriorating agricultural conditions. As already discussed, it might be difficult to distinguish them from economic migrants. At the same time, these migrants would constitute a much bigger burden to share among industrialized nations.

According to the second principle, support should be proportional to one's country's capacities regarding population size, economic situation, and past number of accepted migrants. Large states that have the financial means and a relatively small migrant population should accept more migrants than others. According to Bansak et al. (2017), this principle of 
proportional equality should receive wide support as it constitutes one of the most fundamental principles of burden sharing that is also applied as a principle of distributive justice.

While the principles of general moral obligation and proportional equality concern immigration questions in general, there is a third principle that is particularly relevant to the debate on climate change migrants: corrective justice (Wyman 2013). It is widely agreed that emissions in industrialized states are the main cause of climate change, which at present affects developing countries more than developed countries. Almost $90 \%$ of the participants in the survey agreed that the effect of human beings' behavior on climate change is very or rather strong, which in turn strongly affects the environment. According to Byravan and Rajan (2010), the problem is not so much that industrialized states emit greenhouse gases but that they emit so much more per capita than developing countries and at the same time also benefit disproportionately from these developments. It can thus be argued that Western societies have a special obligation to accommodate climate change migrants.

Against the corrective justice principle, it might be argued that current citizens of a country are not responsible for harms caused in the past, that earlier emitters might not have known the consequences of their behavior, and that it is in general difficult to relate a country's emissions to migration flows of specific groups, especially given the complexity of migration patterns (Wyman 2017: 353).

In any case, whether or not one agrees with any of these arguments might depend on whether or not this would indeed lead to substantial increases in migration. As Germany is a rich and attractive industrial country, it might potentially be confronted with a high number of climate change migrants. The question is thus whether there might be a trade-off between moral principles and a sense of corrective justice, on the one hand, and very blatant selfinterests regarding the costs of immigration, on the other hand. Even those who defend the principle that vulnerable people need to be assisted, irrespective of the reason for that vulnerability, argue that this can be done as long as a country can bear the costs (Rawls 1971).

To test whether or not cost-related arguments affect the respondents' willingness to accept climate change migrants, the survey sought to elicit participants' self-interest by providing arguments for the potential number of climate change migrants (Bansak et al. 2017). While there seems to be a broad agreement that climate change has an important direct or indirect impact on migration flows, studies continue to debate whether or not these migrants move to Western countries. It has, for example, been shown that climate change leads first and foremost to internal migration and urbanization (Beine and Parsons 2015).

To test which justifications make the acceptance of climate change migrants more likely, participants were asked to indicate their agreement with various statements on reasons to accept climate change migrants. Each participant received one vignette, and they were as follows (randomizing the parts in italics; for balance tests see Table 4 in Appendix):

In the near future, more and more people will be forced to leave their home countries due to deteriorating environmental conditions such as floods and droughts that some say are caused by climate change. Various researchers anticipate that a relatively small/high number of these migrants migrate to industrialized countries such as Germany as most of them migrate to neighboring countries/as their neighboring countries have similar problems.

Some people argue that industrialized countries like Germany have to help these people as they have a moral obligation to help people in distress in general/as these countries contributed significantly to causing climate change through their greenhouse gas emissions. This support should be proportional to their environmental responsibility 
that leads to climate changelas they have the financial means to do so. This support should be proportional to a country's capacity in relation to financial means, size of the country, and past migration acceptance rates.

Graph 3 displays the marginal means of how much people agree on a scale from 1 (fully no) to 4 (fully yes) with the three arguments, as well as the average agreement values across all three treatment groups when participants were told that climate migration flows will be relatively low or relatively high (see Table 1 in the Appendix for question wording). We see that people become more tolerant when they hear arguments related to capacity instead of morality or corrective justice. The difference, however, is not statistically significant, as indicated in Table 7 in the Appendix. Agreement rates are also higher when a low number of migrants can be expected. This difference is statistically significant.

It should be considered that patterns might vary between subgroups. It is possible, for example, that the corrective justice argument plays a more important role for highly educated people and environmentalists, as they feel more obligation and as this principle might be seen as part of universal liberal norms. Graph 4 displays the same subgroups as Graph 2 (see also Table 7 in Appendix). Two patterns can be observed: people who do not differentiate at all between the different arguments as well as the information provided and those who do. Low-educated people and environmentalists have relatively low and high agreement rates, respectively. Low-educated people have a higher likelihood to be intolerant, and it appears that none of the arguments leads them to rethink their opinions. Environmentalists can be expected to have generally positive feelings towards migrants, as ecological attitudes and tolerance can be explained by similar factors such as postmaterialism and political liberalism, and this is the case irrespective of the arguments provided. These high agreement rates might also be due to their overall sensitivity to environmental and thus climate change issues.

Contrary to low-educated people and environmentalists, highly educated people and nonenvironmentalists were convinced more by the capacity arguments than the other two groups and also reacted differently to the information about low and high migration numbers. In both

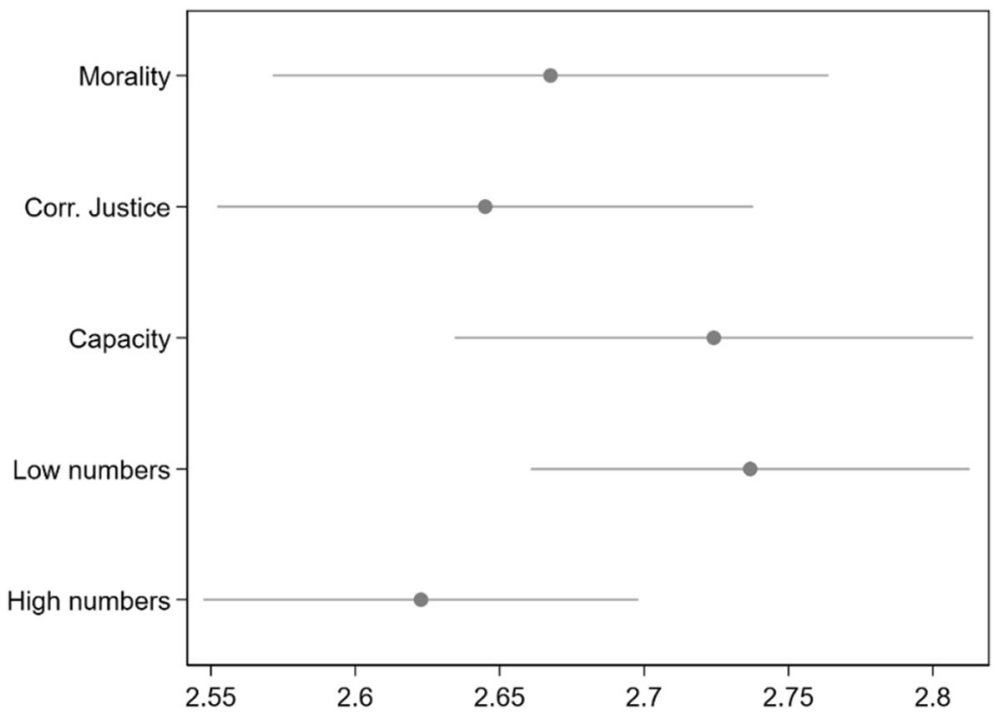

Graph 3 Justifications and self-interests. Marginal means of agreement with different arguments to accept climate change migrants. Point estimates with $95 \%$ confidence intervals (CI). $N=1^{\prime} 102$. For more details, see Table 7 in the Appendix 
cases, the difference between high and low numbers is statistically significant. The difference between the capacity and the other two arguments is statistically significant in the case of nonenvironmentalists but falls short of statistical significance in the case of highly educated respondents (see Table 7 in the Appendix).

\section{Conclusion}

Overall, the results show that Germans are relatively open towards climate change migrants, even in the context of violent and polarized debates over high inflows of migrants that occurred during the period the survey was fielded. Respondents drew a clear distinction between migrants that are perceived as in need of protection or not. In the eyes of the participants, climate change migrants belong to the former. This is a strong indication that the introduction of a legal category - as in the case of political refugees - might find large popular support.

The fact that it does not yet constitute a clearly delimited legal or even social category might also explain the high acceptance rate. Current debates revolve almost exclusively around economic and political migrants. Migration caused by environmental changes has not yet become an important part of public debates. It might therefore be perceived as a rather minor phenomenon that can easily be dealt with. It became clear that the size of the migrant population plays a role when people were told that either high or low numbers of climate change migrants can be expected. Support declines as the number of migrants increases.
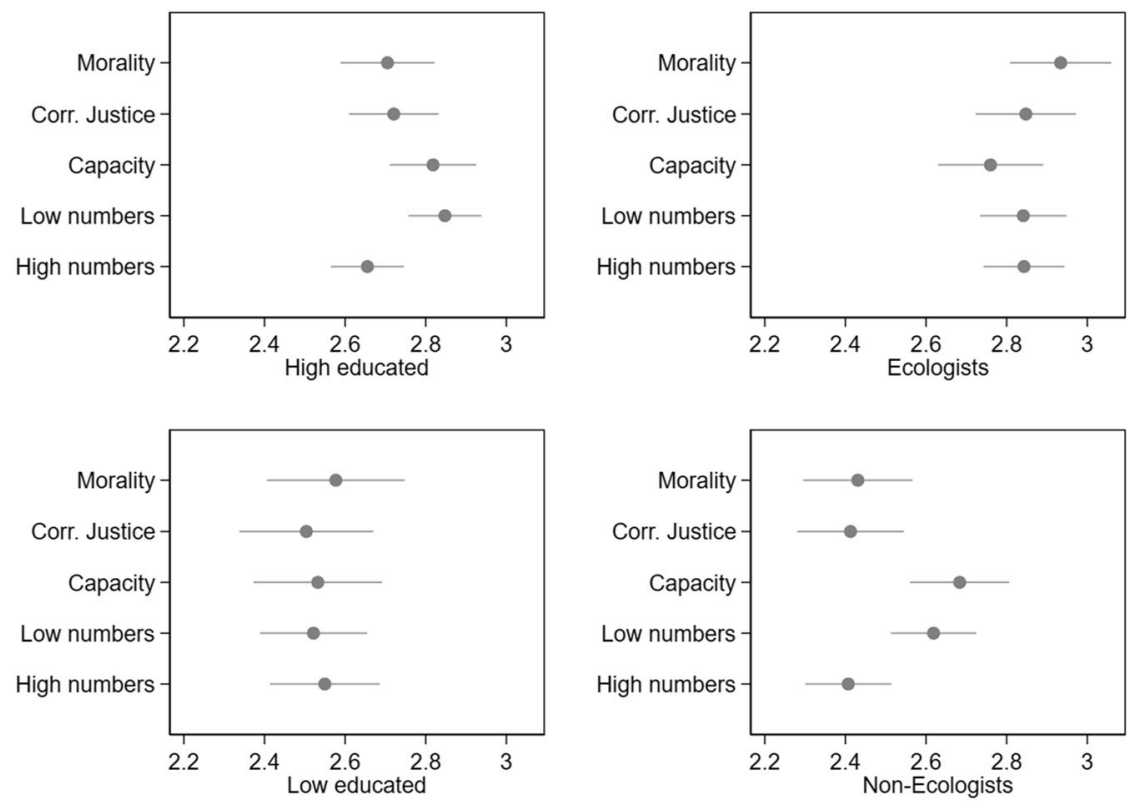

Graph 4 Justifications and self-interests across subgroups. Marginal means of agreement with different arguments to accept climate change migrants. Point estimates with $95 \%$ confidence intervals (CI). $N=1^{\prime} 102$. For more details, see Table 7 in the Appendix 
Investigating the main arguments that could lead one to accept climate change migrants, this paper found that the concrete arguments do not seem to make a big difference. If there is a difference, it mostly relates to the capacity argument. People are willing to accept migrants if they are admitted in proportion to their country's financial means and migration population. This also underlines the finding that material interests play a crucial role and seem to be more important than moral or corrective justice principles.

In recent years in Germany, the wider population was rather supportive of letting in migrants when the first migrants arrived. Later, debates became more polarized when it appeared that migrant inflows had further increased. Such changes mostly happen when the number of migrants increases over a relatively short period of time (Meulemann et al. 2009). Contrary to political migrants, whose numbers can increase heavily over a short period of time due to the outbreak of a war or the coming into power of a new government, the increase in climate change migrants can be expected to be rather slow as climate change is an incremental process. As a consequence, climate change migrants might lead to less opposition than other groups of migrants.

This study constitutes a first step in understanding attitudes towards climate change migrants and under which circumstances and principles people are willing to accept them. Further research is needed to show to what extent the findings of this study can be replicated elsewhere. It might be particularly relevant to investigate industrialized countries in which climate change is not so much seen as a societal and/or environmental problem or where debates about these issues are more polarized than in Germany (McCright et al. 2015). Climate change migrants might also be perceived differently in developing countries that in general receive a larger share of migrants and contribute less to climate change than industrialized countries. Investigating attitudes towards climate change migrants in different contexts might also help us develop new arguments that have not been discussed in this study.

Funding Information Open Access funding provided by Projekt DEAL.

Data availability Data replication sets (dataset and code) are available here: https://doi.org/10.7910 /DVN/MJIVGR.

\section{Appendix}

Table 1 Question wordings

\begin{tabular}{ll}
\hline Items & Question wordings \\
\hline $\begin{array}{l}\text { Acceptance of } \\
\text { immigrants }\end{array}$ & $\begin{array}{l}\text { Do you think Germany should let him immigrate? } \\
\text { Answers: Yes, no }\end{array}$ \\
Treatments & We would now like to discuss the following case of a migrant who likes to come \\
to Germany. He is 29 years old and has no family. He has \\
[Randomize 2 types of migrants] \\
1) A university degree \\
2) A high school degree (Hauptschulabschluss) \\
and is \\
[Randomize 2 types of migrants] \\
1) A Muslim \\
2) A Christian \\
He wants to immigrate to Germany as \\
[Randomize 6 types of migrants] \\
1) He is persecuted for his political convictions in his country due to a new \\
authoritarian regime
\end{tabular}


Table 1 (continued)

Items Question wordings

Agreements with arguments

Treatments

Ecologists 1

Ecologists 2

Ecologists 3

Climate change 1

Climate change 2
2) He cannot find a job in his country due to the increasingly dire economic situation

3) His country is becoming inhabitable due to increasing droughts

4) His country is becoming inhabitable due to increasing droughts caused by climate change

5) His island country is becoming inhabitable due to sea level rises

6) His island country is becoming inhabitable due to sea level rises caused by climate change

Do you agree with these arguments?

Answers: Fully yes, partly yes, partly no, fully no

In the near future more and more people will be forced to leave their home countries due to deteriorating environmental conditions such as floods and droughts that some say are caused by climate change.

[Randomize 2 types of arguments]

1) Various researchers anticipate that a relatively small number of these migrants migrate to industrialized countries such as Germany as most of them migrate to neighboring countries

2) Various researchers anticipate that a relatively large number of these migrants migrate to industrialized countries such as Germany as their neighboring countries have similar problems

[Randomize 3 types of arguments within former arguments]

1) Some people argue that industrialized countries like Germany have to help these people as they have a moral obligation to help people in distress in general

2) Some people argue that industrialized countries like Germany have to help these people as these countries contributed significantly to causing climate change through their greenhouse gas emissions. This support should be proportional to their environmental responsibility for climate change

3) Some people argue that Western countries like Germany have to help these people as they have the financial means to do so. This support should be proportional to its capacity in relation to financial means, size of the country, and past migration acceptance rates

How often do you make a special effort to buy fruits and vegetables grown without pesticides or chemicals?

Answers: Always, often, sometimes, never, where I live there is no fruits and vegetables grown without pesticides or chemicals

How often do you cut back on driving a car for environmental reasons?

Answers: Always, often, sometimes, never, I have no car/drivers' license

How often do you sort glass, cans, plastic or paper and so on for recycling?

Answers: Always, often, sometimes, never, where I live it is not possible to recycle

How strong do you think the effect of climate change is on the environment?

Answers: Very strong, rather strong, rather weak, very weak, there is no climate change

How strong do you think the effect of human beings' behavior is on climate change? Answers: Very strong, rather strong, rather weak, very weak, there is no climate change

Table 2 Descriptive statistics

\begin{tabular}{lllll}
\hline Variables & Means & Std. dev. & Min & Max \\
\hline $\begin{array}{l}\text { Dependent variables } \\
\text { Acceptance }\end{array}$ & 0.60 & & & 0 \\
$\quad$ Agreement & 2.67 & 0.90 & 1 & 4 \\
Respondents & & & & \\
$\quad$ Ecologists & 2.18 & 0.59 & 0 & 4 \\
Highly educated & 0.68 & - & 0 & 1 \\
\hline
\end{tabular}

$N=1^{\prime} 102$ 
Table 3 Balance tests reasons

\begin{tabular}{lllll}
\hline & Political & Economic & Droughts & Sea level rise \\
\hline Age & 43.4 & 44.4 & 45.2 & 44.8 \\
& $(1.2)$ & $(1.06)$ & $(1.15)$ & $(1.07)$ \\
Income bracket & 5.43 & 5.65 & 5.42 & 5.54 \\
& $(0.18)$ & $(0.16)$ & $(0.18)$ & $(0.17)$ \\
Left-right & 5.66 & 5.52 & 5.70 & 5.81 \\
& $(0.14)$ & $(0.13)$ & $(0.16)$ & $(0.15)$ \\
$N$ & 175 & 210 & 168 & 185 \\
\hline
\end{tabular}

Covariate means with standard errors for respondents randomly assigned to each treatment condition in Graphs 1 and 2 . Age varies between 18 and 70 years, income brackets between 0 and 11, and left-right scale between 1 and 11

Table 4 Balance tests arguments

\begin{tabular}{llllll}
\hline & Morality & Corrective justice & Capacities & Low numbers & High numbers \\
\hline Age & 44.1 & 44.9 & 44.4 & 44.9 & 44.1 \\
& $(0.80)$ & $(0.78)$ & $(0.79)$ & $(0.64)$ & $(0.64)$ \\
Income bracket & 5.62 & 5.45 & 5.39 & 5.37 & 5.60 \\
& $(0.12)$ & $(0.11)$ & $(0.13)$ & $(0.10)$ & $(0.10)$ \\
Left-right & 5.76 & 5.72 & 5.53 & 5.69 & 5.64 \\
& $(0.11)$ & $(0.11)$ & $(0.10)$ & $(0.09)$ & $(0.09)$ \\
$N$ & 356 & 369 & 377 & 548 & 554 \\
\hline
\end{tabular}

Covariate means with standard errors for respondents randomly assigned to each treatment condition in Graphs 3 and 4. Age varies between 18 and 70 years, income brackets between 0 and 11, and left-right scale between 1 and 11

Table 5 Immigration acceptance

\begin{tabular}{clllll}
\hline & All & High-skilled & Low-skilled & Environmentalists & Non-environmentalists \\
\hline Ref: Economic & & & & \\
Political & $0.793^{* * *}$ & $0.930^{* * *}$ & $0.650^{\circ}$ & $0.716^{*}$ & $0.833^{* *}$ \\
& $(0.215)$ & $(0.267)$ & $(0.378)$ & $(0.303)$ & $(0.306)$ \\
Droughts & $0.508^{*}$ & $0.445^{\circ}$ & $0.685^{\circ}$ & $0.505^{\circ}$ & $0.499^{\circ}$ \\
& $(0.213)$ & $(0.258)$ & $(0.385)$ & $(0.305)$ & $(0.300)$ \\
Sea level rise & $0.693^{* * *}$ & $0.753^{* *}$ & $0.644^{\circ}$ & $0.715^{*}$ & $0.666^{*}$ \\
& $(0.210)$ & $(0.254)$ & $(0.382)$ & $(0.304)$ & $(0.291)$ \\
Ref: Muslims & & & & & $0.550^{* *}$ \\
Christian & $0.489^{* * *}$ & $0.535^{* * *}$ & $0.391^{\circ}$ & $0.479^{*}$ & $(0.182)$ \\
& $(0.129)$ & $(0.160)$ & $(0.227)$ & $(0.187)$ & $0.424^{*}$ \\
Ref: Low edu. & & & & & $(0.182)$ \\
High educated & $0.565^{* * *}$ & $0.596^{* * *}$ & $0.507^{*}$ & $0.705^{* * *}$ & $-0.717 * *$ \\
Constant & $(0.129)$ & $(0.160)$ & $(0.225)$ & $(0.185)$ & $(0.245)$ \\
& $-0.637^{* * *}$ & $-0.580^{* *}$ & $-0.814^{*}$ & $-0.572^{*}$ & 538 \\
\hline
\end{tabular}

Coefficients of logistic regressions with standard errors in parentheses. Model in first column corresponds to Graph 1 and the other models to Graph 2. Degrees of significance: $* * * p<0.001, * * p<0.01, * p<0.05$, and ${ }^{\circ} p<0.1$ 
Table 6 Immigration acceptance with alternative measure for climate change reasons

\begin{tabular}{|c|c|c|c|c|c|}
\hline & All & High-skilled & Low-skilled & Environmentalists & Non- environmentalists \\
\hline \multicolumn{6}{|l|}{ Ref: Economic } \\
\hline Political & $\begin{array}{l}0.741^{* * *} * \\
(0.180)\end{array}$ & $\begin{array}{l}0.835 * * * \\
(0.218)\end{array}$ & $\begin{array}{l}0.647^{*} \\
(0.329)\end{array}$ & $\begin{array}{l}0.717 * * \\
(0.260)\end{array}$ & $\begin{array}{l}0.743 * * \\
(0.251)\end{array}$ \\
\hline Droughts & $\begin{array}{l}0.439 * \\
(0.180)\end{array}$ & $\begin{array}{l}0.431 * \\
(0.217)\end{array}$ & $\begin{array}{l}0.518 \\
(0.332)\end{array}$ & $\begin{array}{l}0.445^{\circ} \\
(0.262)\end{array}$ & $\begin{array}{l}0.434^{\circ} \\
(0.249)\end{array}$ \\
\hline Sea level rise & $\begin{array}{l}0.839 * * * \\
(0.207)\end{array}$ & $\begin{array}{l}0.881 * * * \\
(0.252)\end{array}$ & $\begin{array}{l}0.830 * \\
(0.372)\end{array}$ & $\begin{array}{l}0.865^{* *} * \\
(0.294)\end{array}$ & $\begin{array}{l}0.749 * \\
(0.295)\end{array}$ \\
\hline \multicolumn{6}{|l|}{ Ref: Muslims } \\
\hline Christian & $\begin{array}{l}0.489 * * * \\
(0.129)\end{array}$ & $\begin{array}{l}0.540 * * * \\
(0.160)\end{array}$ & $\begin{array}{l}0.391^{\circ} \\
(0.224)\end{array}$ & $\begin{array}{l}0.485 * * \\
(0.186)\end{array}$ & $\begin{array}{l}0.543 * * \\
(0.182)\end{array}$ \\
\hline \multicolumn{6}{|l|}{ Ref: Low edu. } \\
\hline High educated & $\begin{array}{l}0.564 * * * \\
(0.129)\end{array}$ & $\begin{array}{l}0.602 * * * \\
(0.160)\end{array}$ & $\begin{array}{l}0.503^{*} \\
(0.224)\end{array}$ & $\begin{array}{l}0.707 * * * \\
(0.185)\end{array}$ & $\begin{array}{l}0.417 * \\
(0.181)\end{array}$ \\
\hline Constant & $\begin{array}{l}-0.637 * * * \\
(0.175)\end{array}$ & $\begin{array}{l}-0.585 * * \\
(0.208)\end{array}$ & $\begin{array}{l}-0.811^{*} \\
(0.328)\end{array}$ & $\begin{array}{l}-0.576^{*} \\
(0.251)\end{array}$ & $\begin{array}{l}-0.710 * * \\
(0.245)\end{array}$ \\
\hline$N$ & 1102 & 745 & 357 & 564 & 538 \\
\hline
\end{tabular}

Coefficients of logistic regressions with standard errors in parentheses. Same models as in Table 5 with alternative measures for "droughts" and "sea level rise" (see footnote 5). Degrees of significance: $* * * p<0.001, * * p<0.01, * p<0.05$, and ${ }^{\circ} p<0.1$

Table 7 Justifications and self-interests

\begin{tabular}{llllll}
\hline & All & High-skilled & Low-skilled & Environmentalists & Non-environmentalists \\
\hline Ref: Low impact & & & & \\
High impact & $-0.112^{*}$ & $-0.194^{* *}$ & 0.030 & 0.001 & $-0.205^{* *}$ \\
& $(0.054)$ & $(0.065)$ & $(0.097)$ & $(0.075)$ & $(0.076)$ \\
Ref: Capacity & & & & & \\
Morality & -0.056 & -0.118 & 0.043 & $0.174^{\circ}$ & $-0.251^{* *}$ \\
& $(0.067)$ & $(0.079)$ & $(0.122)$ & $(0.093)$ & $(0.092)$ \\
Corr. justice & -0.075 & -0.097 & -0.032 & 0.088 & $-0.261^{* *}$ \\
Constant & $(0.066)$ & $(0.080)$ & $(0.115)$ & $(0.089)$ & $(0.094)$ \\
& $2.779 * * *$ & $2.919 * * *$ & $2.520 * * *$ & $2.760^{* * *}$ & $2.787^{* * *}$ \\
$N$ & $(0.054)$ & $(0.065)$ & $(0.092)$ & $(0.072)$ & $(0.076)$ \\
$R^{2}$ & 1101 & 744 & 357 & 564 & 537 \\
\hline
\end{tabular}

Coefficients of OLS regressions with standard errors in parentheses. Model in first column corresponds to Graph 3 and the other models to Graph 4. Degrees of significance: $* * * p<0.001, * * p<0.01,{ }^{*} p<0.05$, and ${ }^{\circ} p<0.1$

Open Access This article is licensed under a Creative Commons Attribution 4.0 International License, which permits use, sharing, adaptation, distribution and reproduction in any medium or format, as long as you give appropriate credit to the original author(s) and the source, provide a link to the Creative Commons licence, and indicate if changes were made. The images or other third party material in this article are included in the article's Creative Commons licence, unless indicated otherwise in a credit line to the material. If material is not included in the article's Creative Commons licence and your intended use is not permitted by statutory regulation or exceeds the permitted use, you will need to obtain permission directly from the copyright holder. To view a copy of this licence, visit http://creativecommons.org/licenses/by/4.0/. 


\section{References}

Bansak K, Hainmueller J, Hangartner D (2016) How economic, humanitarian, and religious concerns shape European attitudes toward asylum seekers. Science 354:217-222

Bansak K, Hainmueller J, Hangartner D (2017) Europeans support a proportional allocation of asylum seekers. Nat Hum Behav 1:0133

Bechtel MM, Scheve KF (2013) Mass support for global climate agreements depends on institutional design. Proc Natl Acad Sci 110(34):13763-13768

Beine M, Parsons C (2015) Climatic factors as determinants of international migration. Scand J Econ 117(2): 723-767

Burson B, Kälin W, McAdam J, Weerasinghe S (2018) The duty to move people out of harm's way in the context of climate change and disasters. Refug Surv Q 37:379-407

Byravan S, Rajan SC (2010) The ethical implications of sea-level rise due to climate change. Ethics Int Aff 24(3): 239-260

Dell M, Jones B, Olken B (2012) Temperature shocks and economic growth: evidence from the last half century. Am Econ J Macroecon 4(3):66-95

Dustmann C, Okatenko A (2011) Review of data and predictions about attitudes to migration and the environment. Foresight Project on Global Environmental Migration, London http://www.bis.gov. uk/assets/foresight/docs/migration/modelling/11-1270-mr5-review-attitudes-to-migration-and-environment

El-Hinnwai E (1985) Environmental Refugees. United Nations Environment Programme, Nairobi

Hager A, Veit S (2019) Attitudes towards asylum-seekers: evidence from Germany. Public Opin Q 83(2):412422

Hainmueller J, Hopkins DJ (2014) Public attitudes toward immigration. Annu Rev Polit Sci 17:225-249

Laczko F, Tjaden J, Auer D (2017) Measuring Global Migration Intention, 2010-2015. GMDAC Data Briefing. International Organization for Migration, global migration data analysis Centre, Berlin

Lancee B, Sarrasin O (2015) Educated preferences or selection effects? A longitudinal analysis of the impact of educational attainment on attitudes towards immigrants. Eur Sociol Rev 31(4):490-501

McAdam J (2012) Climate change, forced migration, and international law. Oxford University Press, Oxford

McCright AM, Dunlap RE, Marquart-Pyatt ST (2015) Political ideology and views about climate change in the European Union. Environ Polit 25(2):338-358

Meuleman B, Davidov E, Billiet J (2009) Changing attitudes toward immigration in Europe, 2002-2007. A dynamic group conflict theory approach. Soc Sci Res 38(2):352-365

Pearson AR, Schuldt JP, Romero-Canyas R (2016) Social climate science: a new vista for psychological science. Perspect Psychol Sci 11:632-650

Piguet E, Pecoud A, de Guchteneire P (eds) (2011) Migration and climate change. Cambridge University Press, Cambridge

Rawls J (1971) A theory of justice. Harvard University Press, Cambridge

Valentino NA, Soroka S, Iyengar S, Aalberg T, Duch R, Fraile M, Hahn K, Hansen KM, Harrell A, Helbling M, Jackman S, Kobayashi T (2019) Economic and cultural drivers of immigrant support worldwide. Brit J Polit Sci 49(4):1201-1226

Verkuyten M (2004) Emotional reactions to and support for immigrant policies: attributed responsibilities to categories of asylum seekers. Soc Justice Res 17(3):293-314

Wyman KM (2013) Are we morally obligated to assist climate change migrants? Law Ethic Human Rights 7(2): $185-212$

Wyman KM (2017) Ethical Duties to Climate Migrants. In: Mayer B, Crepeau F (eds) Research Handbook on Climate Change, Migration and the Law. Edward Elgar, Cheltenham, pp 347-375

Publisher's note Springer Nature remains neutral with regard to jurisdictional claims in published maps and institutional affiliations. 